\title{
The Methodology of Preparation of Students of Vocational Schools and Colleges for Technical Creative Activity
}

\author{
Alimov Normurod Nosirovich ${ }^{1}$ \\ ${ }^{1}$ Dean of "Psychology" faculty at Jizzakh branch of National University of Uzbekistan named after Mirzo \\ Ulugbek,candidate of Pedagogical Sciences, docent. ${ }^{1}$
}

\begin{abstract}
This article describes the psychological and pedagogical basis of preparing students for technical creativity and the role of creative activity in preparing them for creative activity, methods and techniques to solve problems of technical creativity. It also provides an analysis of experimental work carried out to determine the formation of technical creativity skills in the process of theoretical and practical education of students in general subjects, as well as in extracurricular activities.

Keywords: creativity, technical creativity, creative activity, creative activity, creative ability, technical creative activity, creative thinking, technical thinking, proactive approach, creative task, model, problem-based learning, problem situation
\end{abstract}

Article Received: 16th October, 2020; Article Revised: 30th December, 2020; Article Accepted: 08th January, 2021

\section{Introduction}

Implementing the tasks set out in the Action Strategy for the five priority areas of development of the Republic of Uzbekistan in 2017-2021,training highly qualified personnel in accordance with the requirements of the labor market, introducing international standards for quality assessment of education, creating effective mechanisms for implementing innovative scientific achievements.

Resolution of the President of the Republic of Uzbekistan dated September 5, 2018 No PQ-3931 "On measures to introduce new management principles in the public education system" and PF-5812 dated September 6, 2019 "On additional measures to further improve the system of vocational education" In accordance with the Decree of the President of the Republic of Uzbekistan, the ongoing socio-political, socio-economic and other reforms in our country make the further development of the talents of the younger generation, training highly qualified personnel, their active participation in the country's development one of today's priorities.

There is a growing demand for creative professionals, creative thinkers, constantly seeking new solutions to problems for the development of any sector of the economy of the Republic, which is rapidly developing science and technology. This, in turn, requires the formation and development of skills for preparation for professional activities, technical creativity in professionals trained in vocational schools, colleges and technical schools, which is one of the important links in the system of continuing education.

\section{Literature review}

The analysis of scientific research and studies has shown that the problem of developing a person's creative ability and creativity reflected in the following researchers' works: G.Y.Bush [9], S.S.Gusev [10], and the psychological aspects S.L.Rubinstein [19], I.B.Askarov $[4,5,6]$. In the works of V.G Razumovsky [17], E.I Rodjkova [18] and others the didactic aspects of technical creativity, in the works of P.N Andrianov [7] the forms, techniques and methods of organization of technical creativity are analyzed. Issues of development of independent and creative work of students 
were studied by D.Jalolova [11] and others.

The development of technical creativity as a pedagogical problem and others has been shown by psychologists: P.N.Andrianov [7], V.E.Alekseev [2], P.T.Magzumov [14], R.A.Nizamov [15], U.N.Nishonaliev [16], Sh.S.Sharipov [20], Kh.M.Abdullaeva [1] and others, as well as methods of developing technical creativity in the preparation of students for work E.F.Zeer [12] and S.L.Rubinstein [19].

The expediency of acquainting students with the methods of scientific knowledge in technical creativity is emphasized in the works of Yu.K. Babansky [8] and others. A number of studies by T.D.Ismailov [13], Sh.S.Sharipov [20] have considered the issues of improving the training of future teachers of labor education to lead students in technical creativity.

In particular, in the work of T.D. Ismailov the issue of training labor education teachers in pedagogical institutes to lead the technical creativity of students in rural schools was studied on the example of improving the design of agricultural machinery [13].

In the research work of Sh.S.Sharipov the pedagogicalpsychological and organizational conditions of development of creative abilities of future teachers of labor and professional education are defined and substantiated. [20].

Also, the pedagogical scientist I.B. Askarov's work is focused on the research activities of students, and in his work he described the research activities as follows $[3,4,5]$.

Research activity is an activity related to the search for solutions to creative, research problems, the results of which are previously unknown, to provide an active research perspective [6].

In V.E.Alekseev's works the psychological bases of technical creativity, the essence of technical creativity of students, didactic bases of development of technical creativity are defined. In the process of developing technical creativity is based on the polytechnic principle, interdisciplinary connection and the place and role of problem-based learning [2].

\section{Research Methodology}

Usually, the creativity of adults is understood as an activity that leads to the creation of a new, unique product, that is, material and spiritual wealth of social and objective significance. In such an approach, first of all, the result is taken into account, not the process of activity.In the creative activity in the process of teaching and educating young people, the process of formation of individual creativity begins with the formation of the ability to solve non-standard problems that arise in production and problem situations.

We fully agree with this idea, because during the creative activity students should be able to use previously acquired knowledge, skills and abilities (for different purposes, in different contexts), to generalize certain methods of activity, to find new ways to solve problems. Thus, creative activity is the attitude of the subject's activity to his work (job satisfaction, creative motivation in the process of doing it and creative motivation to solve it) and creative problem solving (independent application of previously acquired knowledge, skills and methods of work in a new situation) know) process.

D.B.Bogoyavlenskaya divided creativity into the following three main types:

1) Stimulus-productive activity this is the nature of productivity, which is determined by the influence of some external stimulus. Being at this level reflects a high level of development of mental ability and is exactly the same as the concept of "general ability". 
2) Heuristic activity - it has a creative character. The person continues to analyze the structure and content of his activity, having a sufficiently reliable way of solving the problem, comparing the issues taken separately. All this leads to the creation of new unique ways of solving problems. Each newly discovered law is evaluated by the heurist himself as a discovery, a creative discovery. At the same time, it is seen only as a new method that allows the problem to be solved;

3) Creative. In this case, independently determined empirical laws are not used as a method of solution, but emerge as a new problem.

Creation has long been considered a unique gift of nature, which is not given to everyone. Psychologists emphasize that the necessary qualities for creativity, personal qualities are directly developed in the creative activity of students. Creation is the activity of creating material and spiritual wealth, in which human thinking, memory, imagination, attention and will take an active part, and all knowledge, experience and talent are manifested.

Creation first appears in the human imagination, then research on problems related to it is carried out, the work done by others is critically reviewed, experiments are conducted, logical conclusions are drawn, assumptions are made.

Based on the analysis of research on the problem of the essence of creativity, we came to the conclusion that the essence of creativity is reflected in the following most important features and characteristics:

1) creativity is the highest form of self-expression of a person, in which all his physical and mental forces are actively involved. It is manifested in independent, non-standard activities, the result of which is the creation of material and spiritual values of objective (social) as well as subjective (personal) significance;

2) creativity is always associated with research and long-term initial training as an important manifestation of human activity; creative motivational activity and focus; high level of intellectual development; originality of thinking; high level of ability and independence in relation to the new problem posed; requires the most adequate level of selforganization and self-assessment;

3) creativity should always be built on the basis of humanity.

In our study, we took the following definition of creativity as a working definition:

Creativity is a conscious, goaloriented activity of man aimed at knowing and changing existence, as a result of which new, unique, previously non-existent, material and spiritual blessings are created.

Now, based on this working definition adopted for creativity, we define the content and essence of the concept of "technical creativity".

The concept of "technical creativity" arose in the process of improving the tools of labor and as a result of the division of labor into creative and non-creative types. Technical creativity is just a form of human activity. A characteristic feature of technical creativity is, first of all, that it relies on the results of scientific creativity and seeks ways to put into practice the information related to the development, creation and use of technical systems and devices.

When using technical creativity as a means of developing students' creativity, it is important to take into account the independent importance of the activity at all stages of the creative process. In essence, the independent activity of students is a set of reproductive and creative elements of the activity carried out under the guidance of this teacher.

In technical circles in vocational schools and vocational colleges, students primarily seek to create new technical 
facilities. However, in this case, creativity is a tool of the pedagogical process that seeks to develop the ability in students. This tool is performed by the teacher, not the student.

The purpose of the formation of technical creativity in students in the process of teaching under the guidance of a teacher and beyond is different. It is therefore necessary to limit these types of activities. The technical creativity of students has its ultimate goal, which is determined not only by the creation of socially useful technical and technological objects, but also by the number of cognitive and educational aspects (formation of knowledge, skills, interests and passions in engineering and technology).

Thus, the concept of "technical creativity" is used to describe the following two different processes: 1) the direction of educational work in order to develop students' creativity; 2) creation of creative activity on creation of technical objects. Since this activity can cover all stages of the creative process, then technical creativity is defined as an activity.

Based on the above, taking into account the attempts to define the essence of the concept of technical creativity of students, it can be said that technical creativity of students is a purposeful process of teaching and developing students' technical skills as a result of creating material objects with signs of novelty and usefulness.

Technical creative ability is a set of individual-psychological features that allow students to quickly acquire designtechnological knowledge, skills and abilities in a comfortable environment.

The process of technical creativity, which is characteristic of students of vocational schools and colleges, can be considered as a means of developing technical ability, managing its development, educating a creative attitude to work. The peculiarity of the technical creativity of students can be reflected not in the goals and objectives, but in the nature of technical activity and the didactic issues of teaching technical creativity. In the educational process of vocational schools and vocational colleges, technical creativity should be organized in such a way that the design and technology specific to this or that profession (rationalization of technological processes to increase productivity and quality of products, etc.), as well as improving working methods, rational organization of jobs should be reflected in production and technical issues. This can include preparing students to participate in teamwork, forming a lasting interest in technology, and preparing them for career activities, among others.

Based on this, students' technical creativity is defined as "Technical creativity of students of VS and VC is a mental activity aimed at purposeful change of technological processes and technical objects, using the acquired knowledge, skills and abilities of students and understanding their content. solves technical, technological and production issues, develops new, useful and unique solutions".

Research shows that students' cognitive activity consists of creative and reproductive parts. They are interrelated and in a certain proportion depending on the readiness of the student. The elements of creativity and recollection (memory) differ from each other in terms of results and methods of activity. As a result of creative activity, the student acquires new knowledge or creates educational equipment, devices, tools and more. The novelty of the result of this activity, however, plays an important role in the development of the student's cognitive activity and interest. However, from a didactic point of view, this is not the main and only sign of creativity, it is manifested primarily in the solution of the learning problem and the achievement of the set 
goal. For example, in the study of electricity, it is important to acquaint students with modern trends in electrification. These routes are disclosed through materials related to the receipt, transmission and use of electricity. Concepts such as electric wires, insulator, magnet, electric generator, electric motor, transformer, power transmission line can be basic concepts for studying specific technical objects.

Summarizing the above, we came to the conclusion that creative activity is the activity of applying the skills and competencies acquired by a subject in the process of creating a new product to a situation that is new to him.

Applying the above to technical creative activity and describing the motive, it can be called "actions (or process of action) aimed at solving a problem situation to meet a specific need related to the object of creativity."

Motives for creative activity can take many forms: for example, "striving not to lag behind others"; "Achieving a reputation as a knowledgeable, excellent" and so on. The highest motives are to be creative in order to benefit society, and finally, the motive of "knowing a lot," that is, the motive behind the interest in knowing. The task of the teacher in cultivating and developing the need for creativity in students is to cultivate in them high motives, that is,confidence in the need to be creative in order to "beneficial to society", to develop the need to solve creative problems, to form determination, to be strong.

The specificity of the need motive in the student's activity is also explained by the following: idea, feeling, sadness, objects of the external world, and so on. Need and motive are sometimes combined to form a single concept, that is, to motivate(motivation) them in one word.

The process of creative activity has a wide range of opportunities to shape and meet the needs of the individual. These needs are interpreted in terms of the need to achieve high results and knowledge in the science of psychology.

In our view, this issue can be successfully addressed by ensuring the professional orientation of the general education sciences. Based on this requirement, the teacher discloses the specific objectives of the study of the new law or event in the lesson. Where, in what profession, how, for what purpose, the use of appropriate scientific knowledge shows the importance and necessity of managing their precise production process. The teacher selects a problem production situation and demonstrates how it can be explored using scientific knowledge. For example, when VC students who have chosen the profession of a seamstress are asked the question "Is it possible to sew without a needle?", It is clear that they will answer no. The teacher should then explain to the students that there are ultrawave machines that can sew without a needle. After that, the study of electromagnetic wave scales, wave properties begins.

According to our observations in the training of junior specialists in the field of "Electrical transmission machines, electrical machines and equipment", there are two forms of interrelated teaching of physics and special sciences. In the first case, the teacher goes from teaching physical laws, phenomena and laws to their practical application in special disciplines such as "electric machines", "electrical measuring instruments", "basics of electric drive", "assembly and adjustment of electrical equipment". In the second case, the student applies the laws known to him from the physics course in the process of studying the educational material on the specified special subjects.

Based on the observations, it was found that the relationship between the teaching materials in physics in general 
education subjects and the teaching materials in general subjects can be carried out in the following ways in the lessons organized in special subjects.

1. To explain on the basis of materials based on the laws acquired by students in the study of physics and electrical engineerino

2. To exp The stage of principles of oper emergence of electrical device o: certain physical law

3. Putting in front of students physical laws.

Based on The stage of

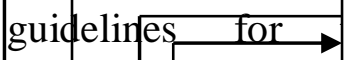
development of tec in VC sudents were emergence and development of a new technical problems that must be used in solving

of mastering the conflict and formulating the problem, a targeted device was created to change the situation. This, in turn, leads to additional psychological stress on the subject and makes the work on the analysis of data, experiments, sources related to the situation under study more active (mobile).

At the same time the stage of

The step to reflect a technical need

The step to identify obvious technical inconsistencies characterized by the uncertainty of the

The step of forming technical issues

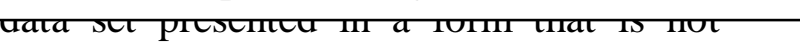
functionally related to the answers. This

The epistemological role of technical creative activity

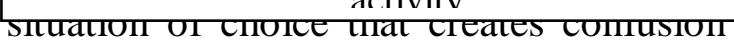
for the subject and encourages him to think

The step of gathering information about an existino technical solution

Basic eative activity in the $\mathrm{VC}$ as an knowledge, and objectives of skills and of future junidr specialists, that

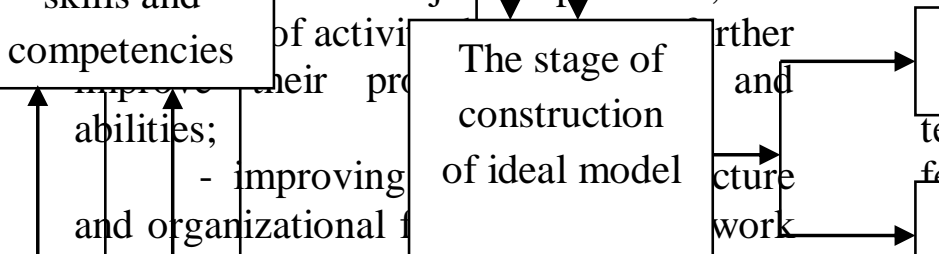
carried out in the VCon the rormation and development of technical creativity in studepts in accordance with modern requinements;

- developm Construction recommendations, of teqhnical creatr inproving the pr competencies of $\mathrm{fu}$ trained in the VC.

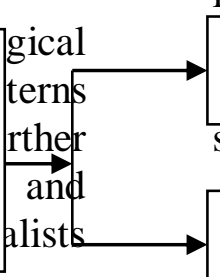

The step of building an ideal model in terms of availahilitv form

technical creativity shows that a distinctive featwre of the technical creativity of adultc The step of building an ideal model in terms of content

of the process of technical creativity consists of several interconnected stages, in which original (unique) methods of

The step to develop the shape of the technical ohiert

significance, material and spiritual wealth. With thic in mind in our atudy we Additional processing step to the developed form students, into the following stages:

Understanding the overall goal and mastering the situar to formulate the $\mathrm{pr}$

Final stage
The step to identify the strengths and weaknesses of the created desion

Processing and additional processing of a new technical ohiert 
Figure 1. The stages of the process of technical creativity of VC students

The first step is to understand the problematic situation. At this stage, the real content of creativity consists in reflecting the technical need, understanding the inadequacy of the old and the need for the new, uncovering, clarifying and formulating specific technical contradictions and specific technical issues.

The real product of the first stage is a clear technical issue that has a definite structure, understood and logically formed. This stage is at the same time the beginning of the solution of a technical problem, the emergence of a technical idea. The second stage is the stage of emergence of a new technical idea. In this case, the technical idea participates as a result of a jump to a new quality in the search for a solution to a particular technical problem. This new quality is still a discovery, not even its ideal model. It is a form of going beyond the direct data, identifying and expressing the previously unknown. At this stage of the process of technical creativity, the epistemological 
role of technical creativity is clearly demonstrated.

The third stage is the stage of creating an ideal model, i.e. the subjective existence of a technical object, the product of intellectual experience and modeling, the result of schematizing a technical idea. Creating an ideal model reflects the process of proving the existence of a technical idea. It is the process of justifying, thinking, and constructing an image of a future technical object.

The ideal model is somewhat simplified in relation to the object to be created, and has a similarity relationship with it. From this basic difference of the ideal model in technical creativity arises the important role of the combined imagination, the activation of knowledge and the conclusion on the similarity of the hypothetical properties and structure of the future technical object with the specific features and structure of existing technical solutions.

In our view, the important role of collecting information on existing technical solutions at this stage stems from the need to form a fund of the nature and structure of existing technical solutions, which is carried out on the activation and similarity of knowledge on the basis of providing a combined vision.

The fourth stage is the construction stage. The main task envisaged at this stage is to develop its form in accordance with the content, taking into account the nature of all objective and subjective factors in the development of this technical object. At the same time, the reader must imagine that there is almost no compatibility in the construction of an ideal model (schemes, structures, etc.) and real design schemes (working projects or layouts). The weaknesses of the intellectual construction are stated, and its suitability is checked by experimental means.

During the design process, additions are made to the established scheme, new design possibilities are identified, new ideas emerge, improvements take place, new options are created. In this case, the novelty is achieved by applying previously known guideline elements to the new content. At this stage, too, it is important to gather information about existing technical solutions as options for the use of certain elements of the design in terms of new content.

The fifth stage is the subjective and relatively complete representation of the technical object. At this stage, the advantages and disadvantages of design and technological developments are identified, all its elements are processed and brought to the norm within the appropriate purpose. Similarly, through the creation and testing of prototypes, the processing and standardization of a new technical object, the development of new techniques and their introduction into various production processes are carried out. This stage serves as the basis for the emergence of new technical issues and a cycle of creative research. Therefore, the process of technical creativity is relatively complete.

Although students' technical creativity is usually manifested as a practical activity, in fact it is gradually enriched with theory, which has allowed technical creativity to be viewed as a complex of both theoretical and practical activities.

Students' technical creativity reflects the activities related to the development and education of their technical thinking and is aimed at applying interdisciplinary theoretical knowledge to practical activities.

Theory is the most important in this activity, because it is the theoretical ideas that are first born, and then they are tested in practice. The development and formation of a theory requires several 
years of observation, research, and experimentation to take place. After that, that is, after the theory has justified itself in practice, it is applied in technical creativity.

Thus, the theoretical basis of students' technical creativity is a set of ideas that complexly express ideas, ideas and views aimed at increasing the effectiveness of their technical creativity.

This is because it is of great methodological and practical importance to take into account the categories of individuality, specificity and generality of dialectics in the activities of technical creativity of students. In the beginning it arises in a special way, then it is strengthened and formed, it becomes special, and then it becomes general, and in this way the solution of many creative problems emerges.

The peculiarity of the technical creativity of students as a system is that the knowledge in it arises due to the presence of laws, concepts that underlie the technological processes and tools of labor in the subjects, optional classes. This system also includes the knowledge of production that students acquire in the learning process.
Another important and key factor in increasing the effectiveness of the educational process in the $\mathrm{VC}$ is the correct organization of a set of technical and creative work of students. This is because the results of any creative work (whether theoretical or practical) have a certain positive role in the creative development of a person, although they are not very important.

They, in turn, are an important tool for activating skills and abilities to quickly and intelligently solve deep problems, thinking, fundamental and individual knowledge, practical problems, are an important form of professional education, in which students form a culture of intellectual and practical work, with scientific and technical achievements,skills and competencies such as acquaintance, essay, course work, diploma work writing, invention are comprehensively developed and improved.

The formation of technical creativity skills in VC students is carried out during class and out of class time. The organizational-structural model of technical creativity of students is shown in Figure 2. 


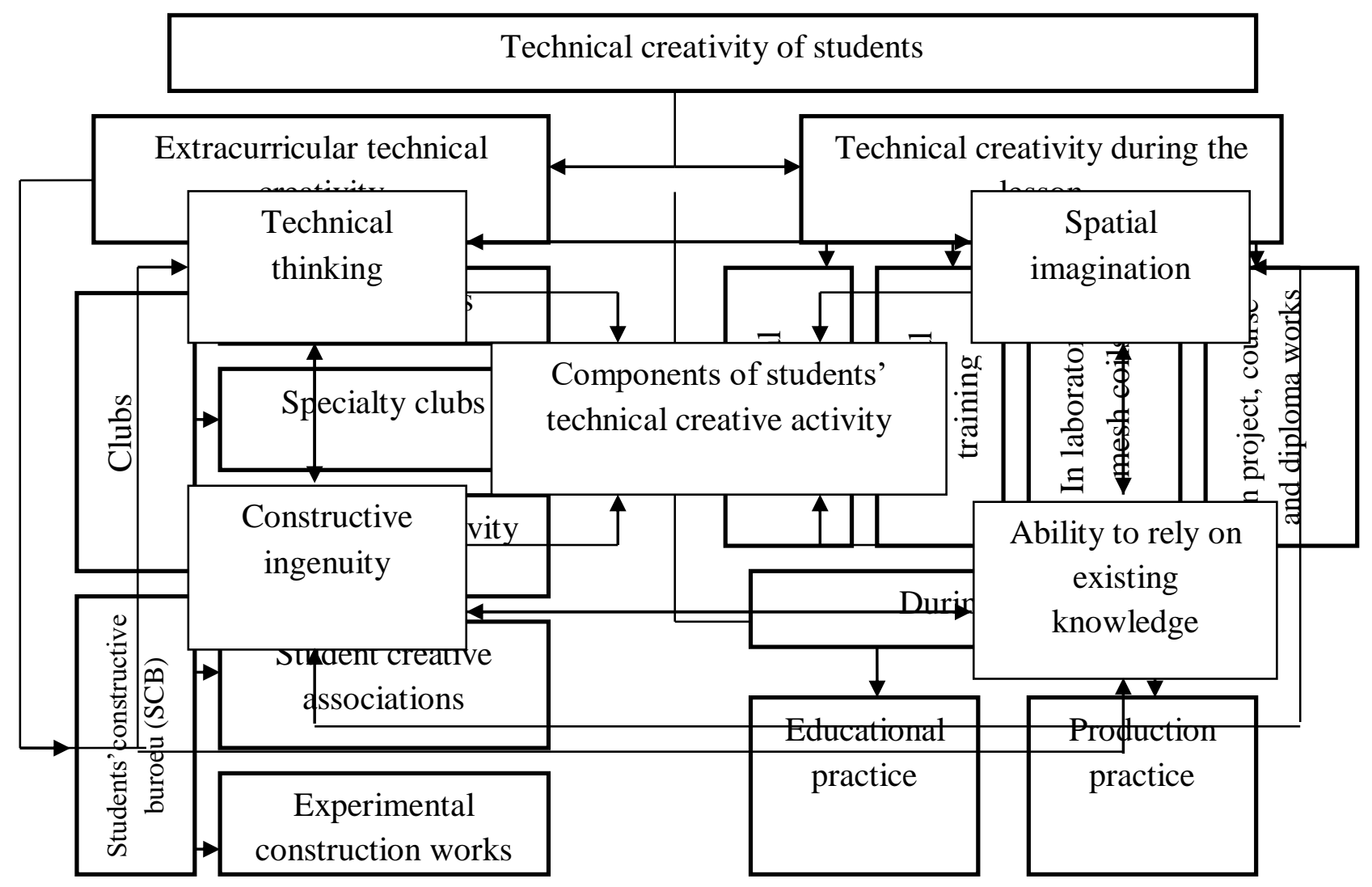

Figure 2. Organizational-structural model of technical creativity of students

The picture shows that students can carry out technical creative activities outside the classroom, in theoretical and practical classes, as well as in practice, and they have different forms.

The types of technical creative activities are diverse and can be complicated by the learning periods (stages) of the students (Table 1).

Continuity of technical creativity of VC students from simple to complex

Table 1

\begin{tabular}{|l|l|}
\hline Stages & Types of technical creative activities \\
\hline \multirow{3}{*}{ I } & $\begin{array}{l}\text { 1. Completion of simple tasks. } \\
\text { 2. Writing essays. }\end{array}$ \\
\hline II & $\begin{array}{l}\text { 1. Performing tasks of medium complexity. } \\
\text { 2. Research activities (course and laboratory work) }\end{array}$ \\
\hline III & $\begin{array}{l}\text { 1. Perform some complex practical tasks. } \\
\text { 2. Creating practical models and layouts. } \\
\text { 3. Completion of more complex practical and theoretical tasks. }\end{array}$ \\
\hline
\end{tabular}

The table shows that the content of a clear work plan of a technical creativity system is complex enough that it can vary depending on the interest of students, at what stage they are learning, the level of basic knowledge and skills, entrepreneurial activity, level of individual skills development and so on.

Thus, there are 4 components in the content of activities aimed at preparing college students for technical creative activity and the development of creative activity in them. These are: technical thinking; spatial imagination; constructive ingenuity; ability to rely on existing knowledge (Figure 3). 


\section{Figure 3 Components of technical creativity of VC students}

These four components are inextricably linked. Therefore, their improvement should be done synchronously and simultaneously. Students' technical creative activity is the result of the dynamic interaction of these key components.

Technical thinking is a complex technical phenomenon. Technical thinking requires knowledge of the language of technology (reading a diagram, scheme, etc.), the presentation of technical objects in the form of a dynamic system of defined goals, its transition from a formal image to a material-objective description and vice versa. This is because technical thinking is manifested through an understanding of the technique, a quick grasp of the structure and operating principles of the technical devices, the identification of existing defects in them, and so on.

In the process of solving problems of technical creativity, research is carried out on the idea of improving a technical object or creating a new technique. This, of course, uses the knowledge acquired in general education and general professional disciplines, as well as the knowledge acquired in special disciplines related to the nature of the problem. In addition, the successful solution of the problem will depend in many respects on the technical nodes of specific techniques that need to be improved, in-depth knowledge of the general laws of development of mechanisms and the correct choice of problem-solving methods. Many creative issues require finding a new method with an original solution, such as mechanization and automation of manual labor, or replacing work that poses a risk to human health with the work of machinery, rather than improving it to overcome existing technical shortcomings.

Any technical system (machine, unit, device, etc.) develops on the basis of its elimination when there is a need to increase the level of performance idealization or when an interference is observed in any part of it relative to another part. As a result, there are various contradictions, including the need to change the whole system or improve part of it. It is also possible that this technique is now completely obsolete and may not justify its authority. At this point, it remains a constructive development stage of the system. In such cases, there is a question of creativity associated with the need to create new techniques.

Solving creative problems requires from the creator unique and necessary practical experience and knowledge about the interaction of details, mechanisms, machines, devices and various nodes. It is especially important to be able to use the 
laws and concepts of physics.

Based on the above, we describe the purpose and function of complex scientific and technical creativity, which is very difficult to solve, with the following set of features.

1. The need to improve the object of technique is unnatural, and the creative process leads to psychological hesitations of the individual or the team. These psychological hesitations can be in the form of "no one has been able to do it yet", "I do not see that we can change the design on our own", "such a problem can be solved only by specially qualified specialists" and so on.

2. The problem under consideration or proposed consists not of solving a simple problem, but of a more complex uncertain situation or uncertain requirements and guidelines for solving the problem (deficiencies in the formation of contradictions in the solution of the problem, lack of clear information about the situation). For example, if we are talking about improving several devices, then it is necessary to replace this obsolete technique with a fundamentally new version.
3. The condition of the problem is given very briefly, simply, in which case it is possible to find the right solution to the problem by correctly analyzing the problem.

4. There may be a need to apply an unfamiliar physical effect in the search for a solution to the creative process.

However, in practice, even when it is possible to identify a technical flaw in a simple system, it still faces a certain psychological barrier to solving it, which can be explained by insufficient knowledge, skills and abilities, lack of self-confidence, lack of information. Therefore, the successful solution of creative problems, including the problem of technical creativity and finding the right solution, requires a clear definition of the goal, the rational finding of effective ways to achieve it, taking into account the existing conditions and resources. In the formation of most creative issues, the problem condition is mainly given and the goal needs to be achieved. The content of solving these creative problems can be expressed in the following scheme (Figure 4).

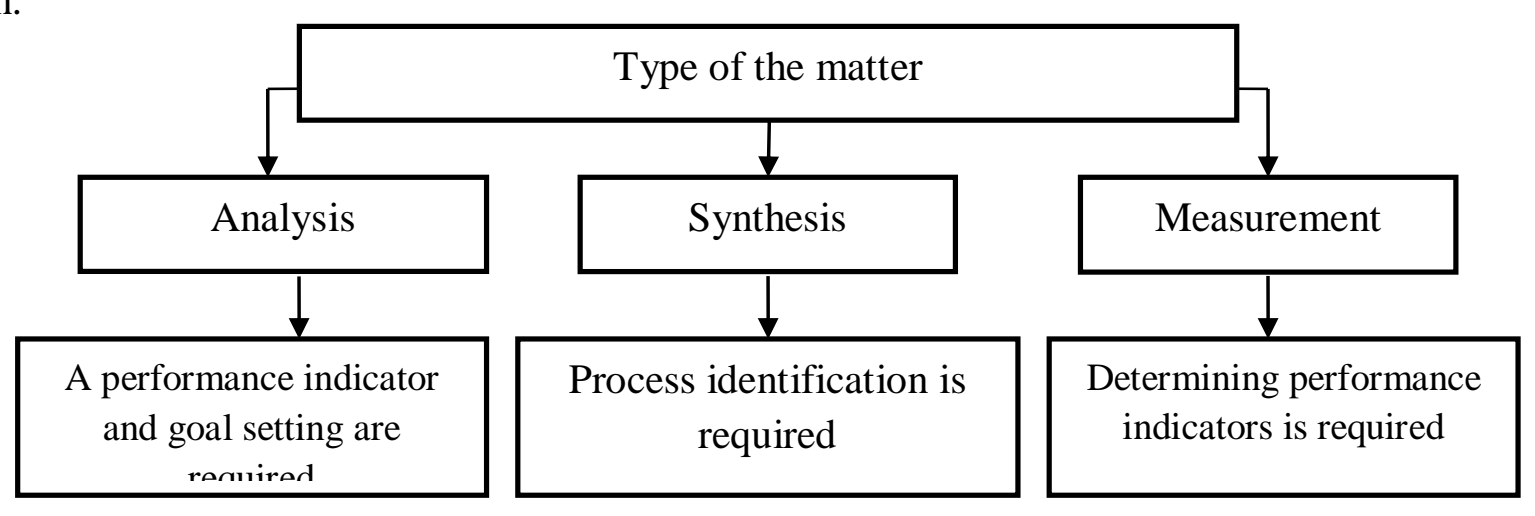

Figure 4. The sequence of solving creative problems

It is necessary to establish the final result in the creative process (system) and conditions given in the problem analysis. For the purpose of the problem synthesis and for the given conditions it is decided how the sequential solution of the considered problem can be carried out, and in the measurement it is provided to establish the description of the conditions of how the required result is achieved.

\section{Analysis and results}

In the process of preparing college students for technical creativity and professional activity, it is very important to 
correctly define the goal. This task includes the actions to be taken in the stages from the beginning to the end of the creative work, the selection of the methodology, control, correction and management.

Questionnaire data were used to identify and develop which clubs students would participate in, and to provide them with initial recommendations in order to find out what popular technical literature they had read. In addition, the results of the first task allow to think about the level of technical and technological readiness of each student and to implement a separate approach to teaching on this basis.

We defined the purpose of the experimental work as the study and evaluation of the methodology of formation of technical creative activity skills in students through the introduction into the practice of VCs.

In organizing the experiments, we set ourselves the goal of solving the following tasks;

1) to check the effectiveness of pedagogical conditions for the preparation of students of professional colleges for technical creative activities in the teaching of general professional subjects;

2) experimental testing of methods of formation of technical creativity skills in students of professional colleges.

Experimental work was carried out in three stages in 2003-2009 in the teaching of general subjects with students majoring in 3502208 - "Power transmission lines, electrical machinery and equipment" in Jizzakh Transport, Communications, Gallaaral Industry,

\section{Table 2}

Assimilation indicators of students who participated in the experimental work

\begin{tabular}{|l|l|l|l|l|l|}
\hline \multirow{2}{*}{ Groups } & \multirow{2}{*}{$\begin{array}{l}\text { Number of } \\
\text { students }\end{array}$} & \multicolumn{4}{|c|}{ Marks } \\
\cline { 3 - 6 } & 2 & 3 & 4 & 5 \\
\hline $\begin{array}{l}\text { Experimental } \\
\text { group }\end{array}$ & $n=74$ & $n_{1}=1$ & $n_{2}=17$ & $n_{3}=35$ & $n_{4}=21$ \\
\hline Control group & $m=76$ & $m_{1}=5$ & $m_{2}=34$ & $m_{3}=26$ & $m_{4}=11$ \\
\hline
\end{tabular}

Students' theoretical knowledge was assessed on the basis of test questions, and their skills and competencies were assessed by completing problematic and practical tasks related
Pakhtakor Agricultural Vocational Colleges.The 150 students from Jizzakh Transport, Communications, Gallaorol Industry and Pakhtakor Agricultural Enterprises took part in the experimental work.Of these participants, 74 of them were experimental and 76 of them were students in the control group.

In the first stage of experimental work (2003-2005) the current state of the research problem in the practice of professional colleges was studied and analyzed, and the experimental areas, that is,professional colleges, where the material and technical base is located, were identified. and the educational environment was studied.

Questionnaires were conducted with students and science teachers in order to determine the creative abilities, interests, aptitudes of students selected for the control and experimental groups from the experimental sites and the level of preparation for technical creative activities in general subjects.

The data on the number of students corresponding to the level of preparation for technical creative activities in the first stage, determined by performing practical tasks and test assignments containing problematic elements in theoretical and practical lessons, are given in Table 2, and the histogram in Figure 5.

The results for the control and experimental groups were systematically analyzed and compared with each other. The results were used as a basis for a reliable conclusion. 
to the replacement of various parts in the blocks and assemblies of electrical equipment, repair and maintenance of electrical equipment.

As can be seen from the diagram (Figure 2), the number of students who received excellent grades in the experimental group in the teaching of "Fundamentals of General Electrical Engineering and Electronics" increased by 14\% compared to the control group, the number of good students increased by $22.1 \%$. , Decreased by $8 \%$, while students with unsatisfactory grades decreased by $5.2 \%$.

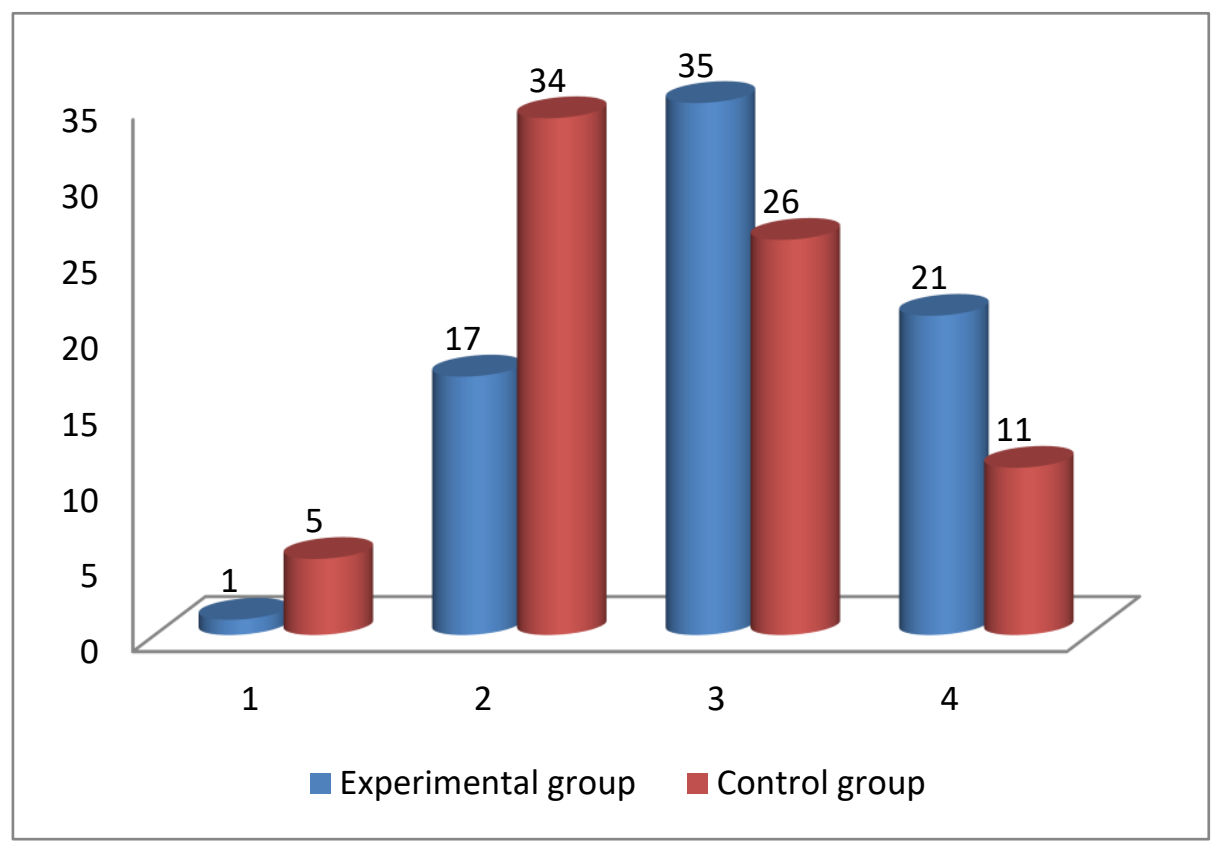

Figure 5. Diagram of the results of experimental work

The experimental results were processed using the Student and Pearson methods of mathematical statistics. To do this, initially the average values of mastering of the control and experimental groups, the corresponding variances were determined by $S_{1}$ and $S_{2}$ :

The correctness or incorrectness was then checked by the following statistics of the Student:

$$
T_{x, y}=\frac{\bar{x}-\bar{y}}{\sqrt{\frac{s_{1}{ }^{2}}{n}+\frac{s_{2}{ }^{2}}{m}}} .
$$

Where: $\bar{x}$ and $\bar{y}$ are the average performance of the experimental and control groups, respectively; $\mathrm{S}_{1}$ and $\mathrm{S}_{2}$ are their sample variances.

It was found from the table that the critical point value corresponding to the reliability probability $P=0,95$ is equal to $t_{0,95}=1,96$. This leads to $T_{x, y}=2,47>1,96=t_{0,95}$ equality.

This leads us to reject the hypothesis $\boldsymbol{H}_{\mathrm{O}}$ and conclude that the mean values of the head sets for both groups are different.

The hypothesis of equality $K_{1}: F_{x}=F_{y}$ of distribution laws for experimental and control groups was tested on the basis of the Pearson criterion: $X_{T}^{2}=\frac{1}{n \cdot m} \sum_{i=1}^{4} \frac{\left(n m_{i}+m n_{i}\right)^{2}}{n_{i}+m_{i}}$.

The equality of the critical point value $Z_{0,95}(3)=7,8$ corresponding to the probability of reliability $\boldsymbol{P}=\mathbf{0 , 9 5}$ and the degree of freedom $v=4-1=3$ was determined from the table. At the same time, this leads to the conclusion that the hypothesis is rejected. The above statistical analysis confirms that 
the teaching methods used in the experimental and control groups are radically different from each other and are more effective in the experimental group.

The results of experimental work led us to conclude that in professional colleges it is possible to achieve efficiency in the organization and conduct of classes on the development of technical creativity of students in general subjects, the use of problem-based learning methods.

\section{Conclusion}

The results obtained during the research on the formation of technical creativity in students in the teaching of general subjects in vocational colleges allowed to draw the following conclusions:

- analyzing the state of training of junior specialists in modern professional colleges, identified psychological and pedagogical bases of their preparation for technical creative activity and clarified the concept of technical creativity.

- on the basis of modern requirements for students of professional colleges, it was determined that the basis of their technical creative activity is the technical principles and general pedagogical principles of solving creative problems, and their content has been developed.

strengthening professional knowledge in preparing students for technical creative activities, developing creative abilities, expanding and developing the polytechnic outlook, forming and developing skills in working with technical devices, mechanisms, machines, structures, interest in creating new devices, improving techniques for creating simple technical devices, a model of engaging students in research activities was developed and the content of its components (components) was highlighted.

- competitions aimed at developing students' technical creativity. Experimental results have shown that the use of non-traditional methods and techniques in the preparation of students for technical creativity in the teaching of general subjects in professional colleges leads to an increase in knowledge and skills of students in technical creativity.

\section{References}

1. Abdullaeva Kh.M. Formation of creative skills in students through professional disciplines // Pedagogical education. $-\mathrm{T} .: 2004$. -№ 6. $-38-40 \mathrm{p}$.

2. Alekseev V.E. Developing creative skills in adolescents. -T .: Teacher, 1992. $88 \mathrm{p}$.

3. Askarov, I.B. (2017). The main stages of training future vocational education teachers for research activities. Eastern European Scientific Journal, (5).

4. Askarov, I.B. (2017). Managing and planning the process of developing research skills and abilities of future vocational education teachers. School of the Future, (2), 10-15.

5. Askarov, I.B. (2017). The main approaches and principles of training future vocational education teachers for research activities. Actual scientific research in the modern world, (2-6), 25-32. 6. Askarov, I.B. (2016). Preparation for research activities of the future teacher of vocational training. In Pedagogical Excellence (pp. 39-42).

7. Andrianov P.N. Development of technical creativity of primary schoolchildren. - M .: Education, 1999 . $109 \mathrm{p}$.

8. Babansky Yu. K. Optimization of the educational process. - M .: Pedagogy, 1982.-190 p.

9. Bush G.Ya. Dialogue and creativity. Riga: Avots, 1985 . -318 p.

10. Gusev S.S, Guseva E.A. Interaction of cognitive processes in scientific and technical creativity. Ed. V. T. Meshcheryakova. - L .: Nauka, 1989 .$125 \mathrm{p}$.

11. Jalolova D.F. Development of independent and creative work activities of 
students in the teaching of special subjects .: Ped. fan. nom. dis. avtoref. ... $-\mathrm{T} .: 2009 .-24 \mathrm{p}$.

12. Zeer E.F. Psychological foundations of the professional formation of the personality-teacher. Author's abstract. diss. ... doc. crazy. sciences. $-\mathrm{L}$.: 1988.$35 \mathrm{p}$.

13. Ismailov T.D. Scientific foundations of training future labor teachers to work on the development of technical creativity of students .: Dis. ... Cand. ped. sciences. $\mathrm{T} . \therefore 1995$. $184 \mathrm{p}$.

14. Magzumov P.T. Pedagogical conditions for the formation of the professional orientation of schoolchildren : Author's abstract. diss. ... Cand. ped. sciences. - M .: 1982 .- 19 p.

15. Nizamov RA Formation of cognitive and practical skills in schoolchildren. UFA. Publish. KSU. 1995 .- 106 p. .$-140 \mathrm{p}$.
16. Nishonaliev U. N. Formation of the personality of a teacher of labor training: problems and prospects - T .: Fan, 1990. $85 \mathrm{p}$.

17. Razumovskiy V.G. Fundamentals of physics teaching methods. $-\mathrm{T} .:$ Teacher, 1984. - 202 p.

18. Rodjkova E.I. Formation of creative activity of students of technical universities by means of modular training: Diss. ... Cand. ped. sciences. - Kaluga, $1991 .-197 \mathrm{p}$.

19. Rubinstein S.L. Fundamentals of General Psychology. Uchpedgiz, 1996 .$642 \mathrm{~b}$.

20. Sharipov Sh.S. Continuous development of students' creative abilities in vocational education. Monograph. Tashkent,

Fan,

2005 